Psychological Medicine, 1990, 20, 755-761

Printed in Great Britain

EDITORIAL

\title{
Is there immune dysfunction in depressive disorders? ${ }^{1}$
}

The hypotheses that psychological disorders result in disturbed immune function, and that such dysfunction, in turn, predisposes the individual to later physical illness, underpin the infant field of 'psychoimmunology'. Despite its short history the discipline has attracted considerable criticism. For example, in a British Medical Journal editorial, Denman (1986) stated that 'little (evidence) suggests that immune reactions are appreciably altered in depressive illnesses' but expressed his principal concern when he concluded 'even if one were to accept that depressive illnesses are associated with perturbed lymphocyte responses, there is sparse evidence that the changes matter'. Similarly, in response to a 1987 Lancet editorial titled 'Depression, stress and immunity', Hall (1987) claimed that 'the effect of psychological factors on the immune response is always marginal and inconsequential and usually undetectable'. We believe that critical examination of the available data should dissuade research workers from abandoning the field prematurely, especially with regard to depressive disorders.

The conclusions of other recent reviews have expressed cautious support for the claim that a significant association between immune dysfunction and depression has been established (Calabrese et al. 1987; Perez \& Farrant, 1988; O'Donnell et al. 1988) although some remain sceptical (King \& Cooper, 1989). All these reviews attempt to avoid the impression that psychoimmunology is merely 'an unholy alliance between the fringes of psychology and immunology' (Hall, 1987).

\section{IMMUNE DYSFUNCTION IN DEPRESSIVE DISORDER}

Dismissal of any association between depression and immune dysfunction may seem justified by a cursory reading of the report of Schleifer et al. (1989) who, in the largest study of its kind, found no substantive differences in humoral or cell-mediated immunity (CMI) between 91 unmedicated patients with major depressive disorder and matched control subjects. It is therefore timely to consider whether 'psychoimmunology' should now be 'cut out and thrown away without any harm being done' (Hall, 1987) or whether methodological issues have obscured important positive findings.

To evaluate the data which directly link depression with immunological abnormalities, clear hypotheses need to be stated. The first hypothesis, that immune dysfunction is directly related to depressed mood, should only be evaluated in studies where immunological assessment has been performed during a current depressive episode. Therefore, in an examination of this hypothesis, the negative finding of studies such as that of Sengar et al. (1982), which was based on the study of patients in remission from depressive disorders, should not be considered. Secondly, if deficient immunity is closely related to the depressive process one might expect an association between severity of depression and the degree of immune dysfunction. If there is such an association, immune measures in patients with mild or transient depressive disorders may not differ significantly from those of normal controls. Thirdly, if mood-related immune deficiency is associated with central nervous system (CNS) dysregulation one might predict that it is specifically associated with the 'endogenous' sub-type of depression, because of the latter's association with other markers of CNS disturbance such as Hypothalamic-Pituitary Axis dysfunction, hypercortisolaemia and shortened REM-sleep latency.

Advances in the understanding of the complex inter-connections between the CNS and the immune system (Cross et al. 1982; Jankovic, 1985; Hall et al. 1985; Blalock et al. 1985; Besedovsky

' Address for correspondence: Dr I. Hickie, Mood Disorders Unit, Prince Henry Hospital, Little Bay, Sydney, NSW 2036, Australia. 
et al. 1985) suggest multiple physiological pathways whereby psychological factors may directly influence host resistance to physical disease. It is the melancholic depressive disorders which are most likely to be associated with known pathways to immune dysfunction, such as hypercortisolaemia (Munck et al. 1984), weight loss (Oppenheim et al. 1975) and disrupted sleep (Palmblad et al. 1979), and, hence, one might expect immune dysfunction to be greater in these patients.

It is commonly accepted that the endogenous sub-type of depressive disorder is more prevalent in older, hospitalized patients, with higher scores on the Hamilton depression scale (Zimmerman et al. 1986, 1989). Therefore, if immune disturbance is restricted largely to the endogenous sub-type, one would predict positive associations between age, severity of depression, hospitalization, and immune dysfunction. In the light of these hypotheses, we now assess the available literature concerning in vitro measures of cell-mediated immune dysfunction in depressive disorders.

Even though the studies reported in the five years prior to the 1989 report by Schleifer et al. were based on small samples, the majority found significant decreases in mitogen-stimulated lymphocyte responses in unmedicated depressed patients as compared with control subjects (Kronfol et al. 1983, 1986; Schleifer et al. 1984; Syvalahti et al. 1985; Calabrese et al. 1986; Darko et al. 1988). Differences have been more distinct in studies of older patients and those hospitalized for more severe depressive disorders, suggesting either that age and/or severity of depression are independent determinants of impaired immunity or that a higher-order CNS disturbance is a cause of both the endogenous sub-type and immune dysfunction. We calculated that the mean age of patients across these studies was almost ten years older than that of depressives in those studies (Albrecht $e t$ al. 1985; Schleifer et al. 1985) which failed to find case-control differences in immune function (47.3 v. 37.9 years, $t=6.05, P<0.001)$. Further, it has been suggested that lymphocyte response to phytohaemagglutinin (PHA) may actually be increased in younger depressed patients as compared with normal controls (Schleifer et al. 1989; Altshuler et al. 1989).

The mean age of those patients with significant immune dysfunction is similar to that which is typically reported in groups of patients with endogenous depression (Kiloh et al. 1972, 1988; Feinberg \& Carroll, 1982; Zimmerman et al. 1985). In 294 consecutive patients evaluated at our Mood Disorders Unit (Brodaty et al. 1987) the mean age of conservatively diagnosed endogenously depressed patients was $50.3(16.5)$ years as compared with $39.4(14 \cdot 1)$ years for non-endogenously depressed patients $(t=6.05, P<0.001)$. Zimmerman et al. (1985) found that patients with endogenous depression, as determined by the Newcastle scale (Carney et al. 1965), were significantly older than patients with non-endogenous depression and that the endogenous diagnosis was significantly associated with failure of suppression on the Dexamethasone Suppression Test (DST), a putative laboratory marker for the endogenous sub-type (Carroll et al. 1981).

One immunological study omitted from our age comparison for methodological reasons was that of Cappel et al. (1978) who compared the peripheral blood lymphocyte responses to PHA of 21 patients hospitalized in the 'acute phase' of 'psychotic depression' (mean age: $56($ S.D. $=10)$ years) with those of 22 control patients. They reported PHA results as 'stimulation indexes', whereby raw scores were divided by unstimulated counts (i.e. at zero concentration of PHA), rather than by the more usual process of subtracting unstimulated counts. As unstimulated counts often vary by as much as a factor of 10 , this transformation may have increased the variance within groups, thereby reducing the chance of detecting between-group differences. We used Cappel et al.'s (1978) tabulated data to calculate differences in PHA responses between the 'acute phase' depressives and control subjects and found a potentially important, albeit non-significant, deficit in the depressed group $(t=1.86, P=0.07)$. Furthermore, the investigators reported that significant PHA 'stimulation indexes' increased following remission of the depressive episodes $(P<0.01)$, supporting the hypothesis that immune dysfunction is state-dependent.

Two studies (Albrecht et al. 1985; Schleifer et al. 1985), conducted principally in younger outpatient samples, failed to find decreased lymphocyte proliferation in response to mitogen stimulation in depressives. The study of Albrecht et al. (1985) involved 27 patients, of whom 18 were reported as suffering from endogenous depression. The mean age of these 18 patients, however, was 
only 34.6 years (range: 21-54) which did not differ from that of the nine non-endogenous depressives ( 35.4 years). The controls, of whom there were only 13, were not sex-matched, and were even younger ( 28.3 years). Thus, the 'endogenous' sample was at best atypical, while the mood disturbance of many of the young patients may well have been too mild to reach a 'biological threshold' associated with immune dysfunction.

Similarly, in the first negative study reported by Schleifer et al. (1985), no differences in lymphocyte responses to mitogen stimulation were found between mildly depressed out-patients and controls. In the larger study recently reported by Schleifer et al. (1989), the investigators found no statistically significant differences between patients and well-matched controls on a range of in vitro cellular immune responses. This sample again consisted mainly of young out-patients. The authors did find negative correlations between increasing age and mitogen stimulation responses (with Concanavalin A (ConA), PHA and Pokeweed mitogen (PWM)) in the depressed patients (ConA : $r=0.26 P<0.02$; PHA: $r=-0.17 \mathrm{NS}$; PWM $: r=-0.16 \mathrm{NS}$ ) and responses fell progressively below those of controls with increasing age over 40 years. A similar relationship was reported for T-inducer (CD4) lymphocyte counts with differences emerging after 45 years of age. Further, there was an inverse association between increasing severity of depression and mitogen stimulation responses (ConA : $r=-0.22, P<0.05$; PHA: $r=-0.21 \mathrm{P}<0.05$; PWM : $r=-0.09$, NS). Although these correlations are small, the results are consistent with the hypotheses that either (i) age and severity are independent determinants of impaired immune function in depressives, or that (ii) such impairments are limited to patients with endogenous depression who are typically older and more severely depressed. In summary, although the 1989 report by Schleifer et al. is undoubtedly the most important investigation yet published in this area, it does not allow a critical evaluation of the fundamental question: is immunological dysfunction largely confined to a depressive sub-type, namely those patients with endogenous depression? Stein (1989), a co-worker of Schleifer, has recently conceded that 'altered immune system measures ... may occur in subgroups of depressed patients'.

\section{DEPRESSIVE SUB-TYPE AND IMMUNE DYSFUNCTION}

A number of studies have addressed this question indirectly. Cosyns et al. (1989), for example, demonstrated more marked impairment in immune function in those patients with the most severe forms of depression. Although patients were not compared with normal controls, typical demographic differences across depressive sub-types were found, namely that younger patients tended to suffer from 'minor' depression, while older patients attracted diagnoses of melancholia. In keeping with other areas of biological research in psychiatry, this study supports the proposition that depressive disorders are heterogeneous and, consequently, that accurate diagnosis of sub-types is essential if distinctive biological abnormalities are to be detected.

\section{Alternative explanations}

It is possible that factors other than depressive sub-type account for the immune dysfunction noted in older groups of depressives. For example, age per se has been associated with progressive impairment in immune function as assessed by in vitro mitogen stimulation of lymphocytes (Oppenheim et al. 1975). Secondly, older age is associated with increasing risk of overt or occult physical diseases, especially malignancies, which may, in turn, have complex associations with immune dysfunction. Thirdly, other factors such as poor nutrition and increased sleep disturbance, which are known to have an impact on immune function (Oppenheim et al. 1975), may be more prevalent in older subjects. All of these factors may contribute in complex ways to the demonstrable immune impairment found in older depressives. Clearly, close age-matching of normal controls and thorough evaluation of the physical health of all subjects are essential in this area of research.

As patients with an endogenous type depression tend to be older and to have a lower genetic loading for affective disorder than younger patients (see Blehar et al. 1988), this type of depression may be a manifestation of a more general bio-psychosocial deterioration or a decreasing ability of 
the person to adapt to environmental challenges. As such the onset of this type of depression may be a 'signpost' to risk of occult physical disease which may, in turn, be associated with deterioration of the immune system and other physiological responses.

\section{Immune cell phenotypes}

The majority of past studies have also examined other measures of immunity such as total white cell count, percentages and absolute numbers of peripheral blood neutrophils, lymphocytes and T-cell subclasses. Clinical interpretation, however, of variations in percentages, or absolute numbers of cell subsets is difficult, as their individual functions cannot yet be judged accurately by their phenotypic characteristics. For example, recent evidence suggests that T-lymphocytes of both the CD4 (T-inducer) and the CD8 (T-suppressor) phenotypes have suppressor activity (Kansas \& Engleman, 1987; Damle, 1987).

A number of psychoimmunological studies have assessed natural killer (NK) cell activity in vitro. Such cells are thought to play a vital role in the body's defences against viral infections and neoplasms (Ritz, 1989), so that a deficit in NK cell activity in depressed patients may have clinical significance. Schleifer et al. (1989) failed to detect differences in NK cell activity in their large study but, given the demographic and diagnostic limitations of their sample, these results should not be considered definitive. By contrast, Irwin et al. (1987) found impaired NK cell activity in a casecontrol study of 19 unmedicated men hospitalized with depression, while Urch et al. (1988) reported that NK cell activity and antibody-dependent cellular cytotoxicity were impaired in both unmedicated and medicated depressed patients. Again, clear definition of depressive sub-types may be the key to a definitive evaluation of any abnormality in NK cell activity in patients with depressive disorders.

We conclude that cell-mediated immune dysfunction, as manifested primarily by decreased lymphocyte responses to mitogen stimulation, has been repeatedly detected in those studies that have investigated older, more severely depressed patients, hospitalized with endogenous rather than non-endogenous disorders.

The demonstration of a reduced lymphocyte proliferative response to mitogen stimulation in such patients does not define a specific functional disturbance of CMI. In vivo methods for assessing CMI, which are yet to be examined adequately in depressed patients, may provide an alternative method for examining clinically relevant defects in cell-mediated immune functioning. Delayed-type hypersensitivity (DTH) skin testing, (which examines the immune system's capacity to recognize, and mount a cell-mediated response against antigens to which the host has been exposed previously), is one such method. Positive skin responses to antigens such as tuberculin, tetanus and candida indicate specific antigen recognition and response by $\mathrm{T}$ cells. Tuberculin positivity has been shown to reflect significant, though incomplete, protection against tuberculosis (Stead 1965; Collins \& Mackaness, 1970). Standard assessment of DTH is available using commercially available kits such as CMI Multitest (Merieux, France) which employs seven different antigens and a glycerin control. Normal ranges for this test system have been established in healthy adult populations (Kniker et al. 1979, 1984).

More sophisticated assessment of CMI may also be achieved by testing the host's ability to mount a response to a novel antigen. For example, a more comprehensive range of immunological mechanisms involved in the mounting of a cell-mediated response to a new specific antigen, such as tuberculin, would include immunization with Bacille Calmette Guerin (BCG) followed by assessment of not only the DTH skin response, but also measurement of T-cell proliferation induced by tuberculin in vitro, mycobacterial antibody production and the production of specific cytokines, such as interleukin-2, gamma interferon, and soluble interleukin-2 receptors by lymphocytes cultured with tuberculin in vitro. 


\section{CLINICAL SIGNIFICANCE OF IMMUNE DYSFUNCTION}

The critical second issue, raised persistently by Hall (1985, 1987), Denman (1986) and Fox (1989) is whether mood-related immune dysfunction has clinical consequences? Direct evidence in support of this hypothesis can only be provided by well-designed longitudinal studies which have yet to be undertaken. Nevertheless, it is important to recognize that psychiatric patients do suffer increased rates of physical illness and death, independent of morbidity and mortality due to accidental injury or deliberate self-harm (Kendler, 1986; Murphy et al. 1989). Specific links between depressive illnesses and infections (Rimon et al. 1971; Lycke et al. 1974; Cappel et al. 1978; Ahokas et al. 1987) autoimmune disorders (Gold et al. 1982; Nemeroff et al. 1985; Legros et al. 1985), cardiovascular disease (Murphy et al. 1989) and malignancies (Shekelle \& Raynor, 1981; Persky et al. 1987) have been reported. Recent reports, however, suggest that depressive symptoms alone do not predict the development of malignancy, even after adjustment for older age (Zonderman et al. 1989; see also Fox, 1989). Similarly, long-term studies of bereaved spouses have not found increased rates of cancer (Helsing et al. 1982; Kaprio et al. 1987). By contrast, distinct depressive syndromes identified in patients over 55 years are associated with a four-times greater risk of death from natural causes at 15 month follow-up (Bruce \& Leaf, 1989), providing indirect support for the hypothesis that immune deficiency and consequent physical morbidity are limited to patients with the endogenous depressive syndrome.

\section{CONCLUSION}

The rapidly developing field of psycho-immunology offers the possibility of revealing the mechanism underlying the putative link between specific depressive syndromes and physical illness. We suggest that critical examination of the available data, while providing some support for the hypothesis that impairment of immune functioning is associated with depressive disorders, points more to the possibility that specific depressive subtypes account for this effect and that these specific subtypes may thereby predispose to physical illness.

Longitudinal studies are now required to determine whether mood-related immune dysfunction associated with specific depressive syndromes is of sufficient magnitude to increase the long-term risk of physical morbidity. Such studies may then allow the direction of causality between immune dysfunction and depressive disorders to be explored further.

I. HICKIE, D. SILOVE, C. HICKIE, D. WAKEFIELD AND A. LLOYD

\section{REFERENCES}

Ahokas, A., Rimon, R., Koshin, M., Vaheri, A.. Julkunen, I. \& Sarna, S. (1987). Viral antibodies and interferon in acute psychiatric disorders. Journal of Clinical Psychiatry 48, 194-196.

Albrecht, J.. Helderman, Journal, H., Schlesser, M. A. \& Rush, A. J. (1985). A controlled study of cellular immune function in affective disorders before and during somatic therapy. Psychiary Research 15, 185193.

Altshuler, L. L.. Plaeger-Marshall, S., Richeimer, S., Daniels, M. \& Baxter, L. R. (1989). Lymphocyte function in major depression. Acta Psýchiatrica Scandinavica 80, 132136.

Besedovsky, H. O., Adriana, E. R. \& Sorkin, E. (1985). Immune neuroendocrine interactions. Journal of Immunology' 135 $750 \mathrm{~s} 754 \mathrm{~s}$.

Blalock, J. E., Harbour-McMenamin, D. \& Smith, E. M. (1985) Peptide hormones shared by the neuroendocrine and immunologic systems. Journal of Immunology 135, 858s 861s.

Blehar, M. C., Weissman, M. M.. Gershon, E. S. \& Hirschfeld, R. M. A. (1988). Family and genetic studies of affective disorders Archives of General Psychiatry 45, 289292.

Brodaty, H., Boyce, P., Wilhelm. K., Mitchell, P. \& Parker, G. (1987). The establishment of a Mood Disorders Unit. Australian \& $N^{\prime}$ ' Z' Z'aland Journal of Psychiatry 21, 375.381.
Bruce, M. L. \& Leaf, P. J. (1989). Psychiatric disorders and 15. month mortality in a community sample of older adults. American Journal of Public Health 79, 727.730.

Calabrese, J. R., Skwerer, R. G., Barna, B., Gulledge, A. D., Valenzueal, R., Butkus, A., Subcihin, S. \& Krupp, N. E. (1986). Depression, immunocompetence, and prostaglandins of the $E$ series. Psychiatry Research 17, 4147.

Calabrese, J. R., Kling, M. A. \& Gold, P. W. (1987). Alterations in immunocompetence during stress, bereavement, and depression, focus on neuroendocrine regulation. American Journal of Psychiatry 144, $1123 \cdot 1134$.

Cappel, R., Gregoire, F., Thiry, L. \& Sprecher, S. (1978). Antibody and cell-mediated immunity to herpes simplex virus in psychotic depression. Journal of Clinical Psychiatry 39, 266268.

Carney, M W. P., Roth, M. \& Garside, R. F. (1965). The diagnosis of depressive syndromes and the prediction of ECT response. British Journal of Psychiatry 111, 659-674.

Carroll, B. J., Tarika, J. \& Albala, A. A. (1981). A specific laboratory test for the diagnosis of melancholia. Standardisation, validation and clinical utility. Archives of General Psychiatry 38, 15-22.

Collins, F. M. \& Mackaness, G. B. (1970). The relationship of delayed hypersensitivity and acquired antituberculous immunity. 
I. Tuberculin sensitivity and resistance to infection in BCGvaccinated mice. Cellular Immunology 1, 253-265.

Cosyns, P., Maes, M., Vandewoude, M., Stevens, W. J., De Clerck, L. S. \& Schotte. C. (1989). Impaired mitogen-induced lymphocyte responses and the hypothalamic pituitary-adrenal axis in depressive disorders. Journal of Affective Disorders 16, 41-48.

Cross, R. J., Brooks, W. H., Roszman, T. L. \& Markesbury, W. (1982). Hypothalamic immune interactions. Journal of the Neurological Sciences 53, 557566.

Damle, N. K. (1987). Immunoregulatory T-lymphocyles in man: soluble antigen specific suppressor-inducer $\mathrm{T}$ lymphocytes are derived from $\mathrm{CD} 4+\mathrm{CD} 45 \mathrm{R}-\mathrm{p} 80+$ subpopulation. Journal of Immunology' 139, 15011508.

Darko, D. F., Lucas, A. H., Gillin, J. C., Risch. S. C., Golshan, S., Hamburger, R. N., Silverman, M. B. \& Janowsky, D. S. (1988). Cellular immunity and the hypothalamic pituitary axis in major affective disorder, a preliminary study. Psychiatry Research 25, 19.

Denman. A. M. (1986). Immunity and depression (editorial). British Medical Journal 293, 464465 .

Editorial. (1987). Depression, stress and immunity. Lancet i, 1467.1468

Feinberg, M. \& Carroll, B. J. (1982). Separation of subtypes of depression using discriminant analysis. I. Separation of unipolar endogenous depression from non-endogenous depression. British Journal of Psychiatry 140, $384-391$.

Fox, B. H. (1989). Depressive symptoms and risk of cancer. Journal of the American Medical Association 262, 1231.

Gold, M. S., Pottash, A. L. C. \& Extein, I. (1982). Symptomless autoimmune thyroiditis in depression. Psychiatry Research 6, $261-269$.

Hall, J. G. (1985). Emotion and immunity. Lancet ii, 326-327.

Hall, J. G. (1987). Depression, stress and immunity. Lancet i, 221.

Hall, N. R., McGillis, J. P., Spangelo, B. L. \& Goldstein, A. L. (1985). Evidence that thymosins and other biologic response modifiers can function as neuroactive immunotransmitters. Journal of Immunology 135, 806s $811 \mathrm{~s}$.

Helsing, K. J., Comstock, G. W. \& Szklo, M. (1982). Causes of death in a widowed population. American Journal of Epidemiology 116. 524532.

Irwin, M., Smith, T. L. \& Gillin, J. C. (1987). Low natural killer cytotoxicity in major depression. Life Sciences 41, 2127 2133.

Jankovic, B. D. (1985). Neural tissue hypersensitivity in psychiatric disorders with immunological features. Journal of Immunology $135,853 \mathrm{~s}-857 \mathrm{~s}$.

Kansas, G. S. \& Engleman, E. G. (1987). Phenotypic identification of suppressor effector, suppressor amplifier and suppressor-inducer $T$ cells and $B$ cell differentiation in man. European Journal of Immunology 17, 453457.

Kaprio, J., Koskenvuo, M. \& Rita, H. (1987). Mortality after bereavement: a prospective study of 95,647 widowed persons. American Journal of Public Health 77, 283-287.

Kendler, K. S. (1986). A twin study of mortality in schizophrenia and neurosis. Archives of General Psychiatry 43, 643-649.

Kiloh, L. G., Andrews, G., Neilson, M.\& Bianchi, G. N. (1972). The relationship of the syndromes called endogenous and neurotic depression. British Journal of Psychiatry 121, 183-196.

Kiloh, L. G., Andrews, G. \& Neilson, M. (1988). The long-term outcome of depressive illness. British Journal of Psychiatry 153, 752.757.

King, D. J. \& Cooper, S. J. (1989). Viruses, immunity and mental disorder. British Journal of Psichiatry 154, 1-7.

Knicker, W. T., Anderson, C. T. \& Roumiantzeff, M. (1979). The multitest system: a standardized approach to evaluation of delayed hyper-sensitivity and cell-mediated immunity. Annals of Allergy 43, $73-79$.

Knicker, W. T., Anderson, C. T., McBryde, J. L., Roumiantzeff, M. \& Lesourd, B. (1984). Multitest CMI for standardized measurement of delayed cutaneous hypersensitivity and cell-mediated immunity. Normal values and proposed scoring system for healthy adults in the USA. Annals of Allergy 52, 75-82.

Kronfol, Z., Silva Jr, J., Greden, J., Dembinski, S., Gardner, R. \&
Carroll, B. (1983). Impaired lymphocyte function in depressive illness. Life Sciences 33, 241247.

Kronfol, Z., House, J. D., Silva Jr. J.. Greden, J. \& Carroll, B. J. (1986). Depression, urinary free cortisol excretion and lymphocyte function. British Journal of Psichiatry 148, 7073.

Lycke, E., Norrby, R. \& Roos, B. E. (1974). A serological study on mentally ill patients with particular reference to the prevalence of herpes virus infections. British Journal of Psychiatry 124, 273279.

Legros, S., Mendlewicz, J. \& Wybran, J. (1985). Immunoglobulins, autoantibodies and other serum protein fractions in psychiatric disorders. European Archives of Psichiatry and the Neurological Sciences 235. 911.

Munck, A., Guyre, P. M. \& Holbrook, N. J. (1984). Physiological functions of glucocorticoids in stress and their relation to pharmacological actions. Endecrine Review 5, 2544.

Murphy, J. M., Monson, R. R., Olivier, D. C., Sobol, A. M., Pralt, L. A. \& Leighton, A. H. (1989). Mortality risk and psychiatric disorders. Results of a general physician survey. Social Psychiatry 24, 134142.

Nemeroff, C. B., Simon, J. S. \& Haggerty, J. J. (1985). Antithyroid antibodies in depressed patients. American Journal of Psychiarry 142, 840-843.

O'Donnell, M., Silove, D. \& Wakefield. D. (1988). Current perspectives on immunology and psychiatry. Australian \& Ne'w' Zealand Journal of Psychiatry 22, 366382.

Oppenheim, J. J., Dougherty, S., Chen, S. C. \& Baker, J. (1975). Utilization of lymphocyte transformation to assess clinical disorders. In Lahoratory Methods in Cell-Metiated and Tumor Immunity (ed. G. N. Vyas), pp. 87 109. Academic Press: New York.

Palmblad, J., Petrini, B. \& Wasserman, J. (1979). Lymphocyte and granulocyte reactions during sleep deprivation. Psichosomatic Medicine 41, 273278.

Perez, M. \& Farrant, J. (1988). Immune reactions and mental disorders. Psichological Medicine 18, 1113.

Persky, V. W., Kempthorn-Rawson. J. \& Shekelle, R. B. (1987). Personality and risk of cancer: 20-year follow-up of the Western Electric Study. Psychosomatic Medicine 49, 4.35 449.

Rimon, R., Halonen. P., Anttinen, E. \& Evola, K. (1971). Complement fixing antibody to herpes simplex virus in patients with psychotic depression. Diseases of the Nervous System 32. 822.824

Ritz, J. (1989). The role of natural killer cells in immune surveillance. New' England Journal of Medicine 320, 17481749.

Schleifer, S. J., Keller, S. E., Meyerson, A. T., Raskin, M. J., Davis, K. L. \& Stein, M. (1984). Lymphocyte function in major depressive disorder. Archives of General Psychiatry 41, 484486.

Schleifer, S. J., Keller, S. E., Siris, S. G., Davis, K. L. \& Stein, M. (1985). Depression and immunity. Archives of General Psychiatry 42, 129-133.

Schleifer, S. J., Keller, S. E., Bond, R. N., Cohen, J. \& Stein, M. (1989). Major depressive disorder and immunity. Archives of General Psychiatry 46, 81-88.

Sengar, D. P. S., Waters, B. G. H., Dunne, J. V. \& Bouer, I. M. (1982). Lymphocyte subpopulations and mitogenic responses of lymphocytes in manic-depressive disorders. Biological Psychiary 17, $1017 \cdot 1022$.

Shekelle, R. B. \& Raynor, W. J. (1981). Psychological depression and 17-year risk of death from cancer. Psychossmatic Medicine 43, 117-125.

Stead, W. W. (1965). The pathogenesis of pulmonary tuberculosis among older persons. American Revie'w of Respiratory Diseases 91. $811-822$.

Stein, M. (1989). Stress, depression and the immune system. Journal of Clinical Psychiatry 50, 35s 40s.

Syvalahti, E.. Eskola, J., Ruuskanen, O. \& Laine, T. (1985). Nonsuppression of cortisol in depression and immune function. Progress in Neuro-Psichopharmacology 9, 413422.

Urch, A., Multer, C. H., Aschauer, H., Resch, F. \& Zielinski, C. C. (1988). Lytic effector cell function in schizophrenia and depression. Journal of Neuroimmunology 18, 291301.

Zimmerman, M., Coryell, W., Pfohl, B. \& Stangl, D. (1985). Four 
definitions of endogenous depression and the dexamethasone suppression test. Journal of Affective Disorders 8, 3745.

Zimmerman, M., Coryell, W., Pfohl, B. \& Stangl, D. (1986). The validity of four definitions of endogenous depression. II. Clinical, demographic, familial and psychosocial correlates. Archives of General Psivchiatry 43, 234244.
Zimmerman, M., Black, D. W. \& Coryell, W. (1989). Diagnostic criteria for melancholia. Archives of General Psychiatry 46, 361-368.

Zonderman, A. B., Costa, P. T. \& McCrae, R. R. (1989). Depression as a risk for cancer morbidity and mortality in a nationally representative sample. Journal of the American Medical Association 262, $1191-1195$. 